\title{
A Rare Case of Eagle Syndrome Associated with Tonsil Hypertrophy: Case Report with Literature Review
}

\author{
Haimedah Edde D ${ }^{1}$, Radhi M EL Hafed ${ }^{1 *}$ and G Cheikh ${ }^{2}$ \\ ${ }^{1}$ ENT department, Military Hospital of Nouakchott, Mauritania \\ ${ }^{2}$ Radiology department, Military Hospital of Nouakchott, Mauritania
}

*Corresponding author: Radhi M EL Hafed, ENT department, Military Hospital of

Nouakchott, Mauritania.

Received Date: June 07, 2021

Published Date: July 01, 2021

\begin{abstract}
Eagle's syndrome, or stylohyoid complex syndrome, is a rare facial pain syndrome characterised by latero-cervical pain radiating to the face, pharyngeal pain increased by swallowing, linked to an abnormal enlargement of the styloid or calcification of the stylo-hyoid ligament. The incidence of the presentation is about 4 to 8 per 10,000 individuals. The establishment of the diagnosis is a challenge in itself as we need to differentiate it from the neuralgias of cranial nerve such as glossopharyngeal neuralgia and superior laryngeal neuralgias. The surgical management of the Eagle syndrome consists in the shortening of the elongated styloid process, with the surgical access by intra oral or cervical. We report a case of a 28-yearold men admitted to our otorhinolaryngology department with sharp neck pain and a sensation of having a foreign body in the throat. Physical examination found bilateral tonsilar hypertrophia, with palpation of a solid immobile structure. CT scan with 3D reconstruction revealed elongated styloid processes with ossification of the left stylo-hyoid ligament. The patient was treated by tonsillectomy with excision of styloid processes by intra oral approach.
\end{abstract}

Keywords: Eagle syndrome; Tonsil hypertrophy; Intra oral surgery

\section{Introduction}

Eagle's syndrome, or stylohyoid complex syndrome, is a rare facial pain syndrome characterised by latero-cervical pain radiating to the face, pharyngeal pain increased by swallowing, linked to an abnormal enlargement of the styloid or calcification of the stylo-hyoid ligament. Hyperplasia of these anatomical structures may develop as the result of trauma, genetic conditions, surgical procedures, or hormonal disorders [1,2]. Described more than a century ago [3], this condition remains an enigma and patients are usually found beingcross-referred from outpatient departments of neurology, dentistry, surgery and otorhinolaryngology. The average length of the styloid process has been determined to be $15.4-18.8 \mathrm{~mm}$ in Asian population and $20-30 \mathrm{~mm}$ in Caucasian population [4]. The incidence of the presentation is about 4 to 8 per 10,000 individuals.
The establishment of the diagnosis is a challenge in itself as we need to differentiate it from the neuralgias

of cranial nerve such as glossopharyngeal neuralgia and superior laryngeal neuralgias. Furthermore, the decision of kind surgical approach; intra oral surgery or trans cervical is another dilemma in itself. We report a case of a 28 -year-old men with classic Eagle's syndrome associated with bilateral tonsil hypertrophy treated in our department by intra oral surgery. The patient remained asymptomatic until this day.

\section{Case Presentation}

28-year-old man presented to our otorhinolaryngology department with sharp neck pain and a sensation of having a foreign body in the throat aggravated on swallowing or in turning 
his head to the right side, symptoms that had developed during the nine past months. At times the pain extended to his right ear. There was no history of trauma or infection. On physical examination, no abnormality was present in the neck, thyroid, ear, sinuses or lymph nodes. Video laryngoscopy produced normal results as well. Thorough intraoral examination had been performed to rule out any source of dental infection and was unremarkable. In the region of the left tonsillar pillar, we found bilateral tonsilar hypertrophia, also a solid and immobile structure was palpated. The patient reported pain during palpation.

Computed tomography with 3D reconstruction revealed (Figure1) left elongated styloid processes measuring $3.9 \mathrm{~cm}$ with ossification of the stylo-hyoid ligament, the right styloid process was normal. A diagnosis of Eagle's syndrome was made. The treatment option was surgical excision of the styloid processes with tonsillectomy. The chosen access was intraoral approach (Figures $2,3)$. The patient underwent general anaesthesia with nasotracheal intubation. With the patient's mouth at the range of maximum opening, we first performing bilateral tonsillectomy, the region of the tonsillar pillar was palpated, indicating the location for incision with the electrocautery.

Tissue dissection was performed and the styloid processes were located. The tissue was dissected till the most proximal portion of the styloid processes. During surgery, an elongated styloid process was visualized and removed with a forceps and then incisions were closed with simple continuous 4-0 vicryl sutures. Symptoms resolved immediately after surgery. On follow-up 7 months after surgery, the patient remained asymptomatic and pain-free (Figures 1-3).

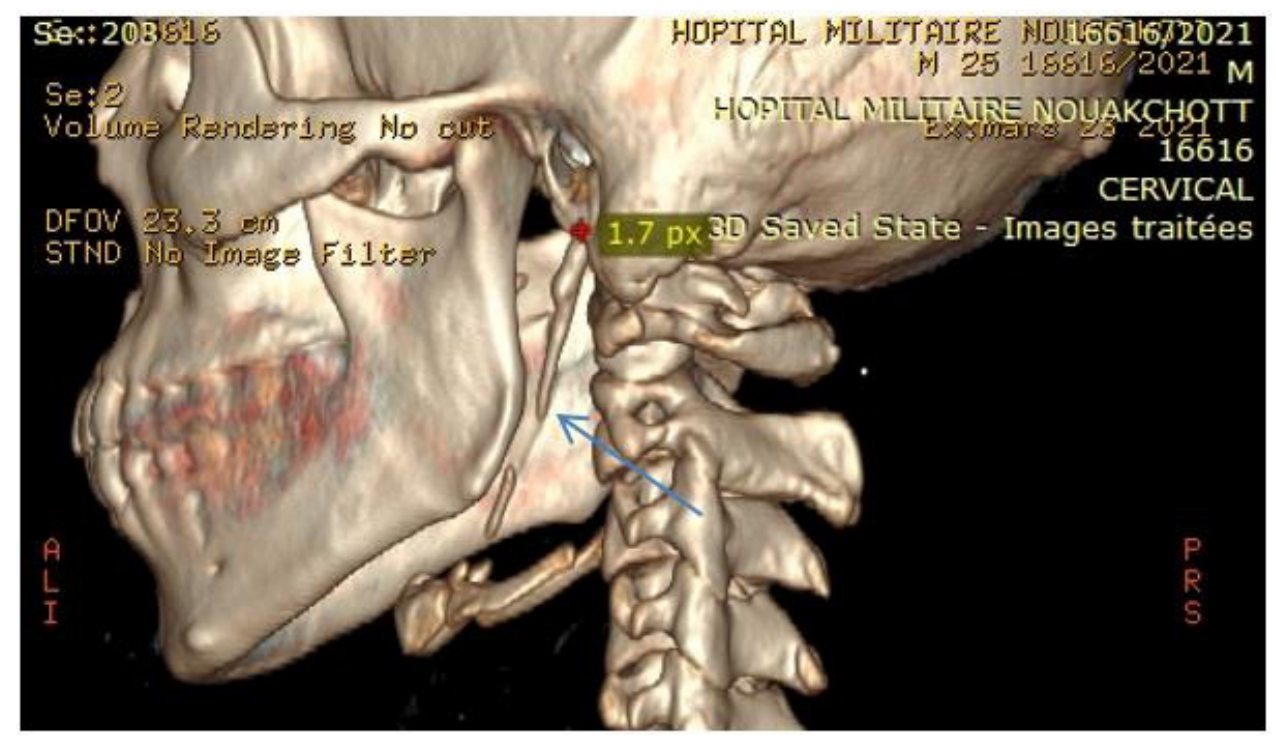

Figure 1: 3D Ct scan showed elongated lef styloid precessess with calcification of stylo hyoid ligament (arrow blue).

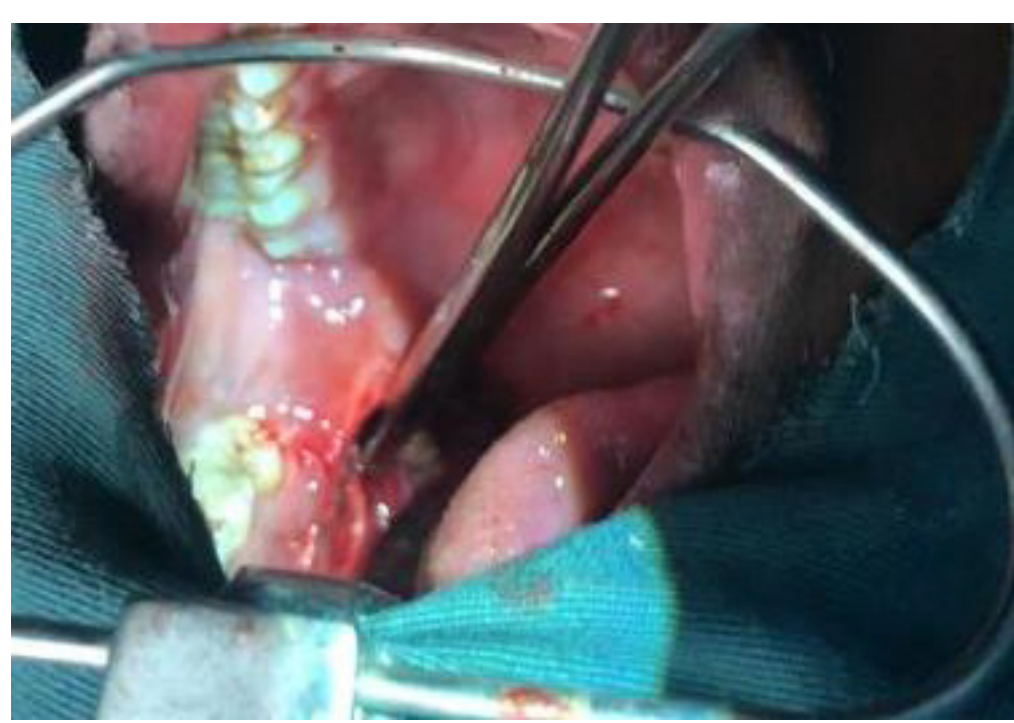

Figure 2: Per operative image of styloid processes. 


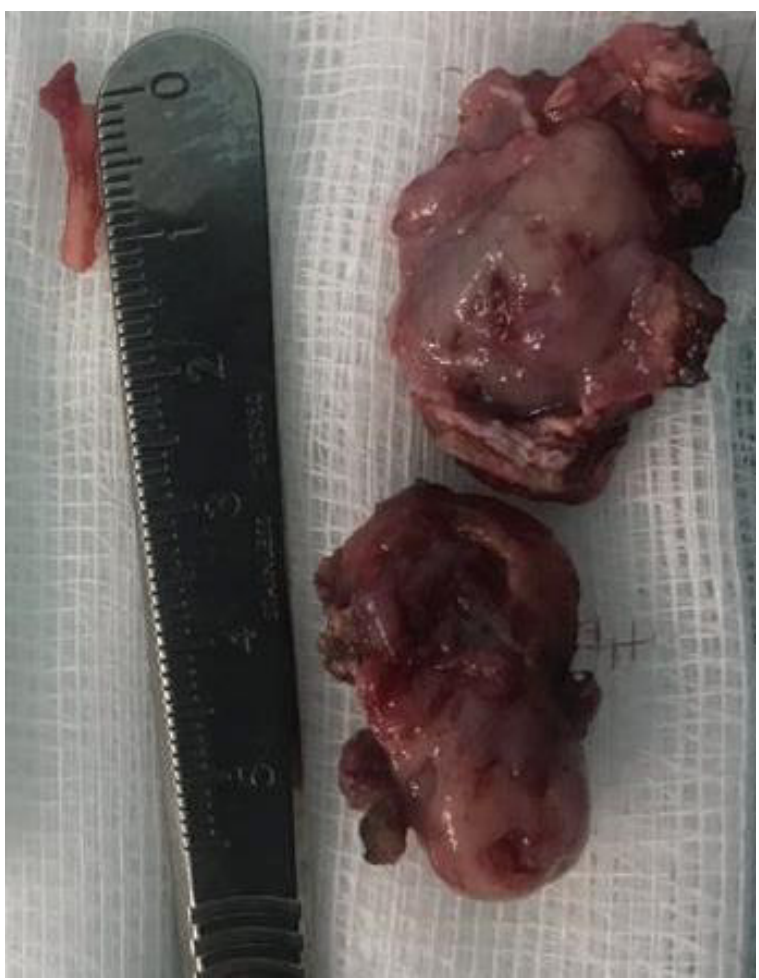

Figure 3: Post operative image of the two tonsil and styloid processes.

\section{Discussion}

Eagle first described two syndromes associated with elongation/ aberrant ossification of the stylo-hyoid apparatus. The first, classic Eagle syndrome was described as pain, dysphagia, and a foreign body sensation that presents immediately after tonsillectomy. Eagle also described stylocarotid sydrome in which an elongated styloid compresses the carotid artery and results in pain (parietal/ periorbital), visual disturbances, and syncope [5]. The diagnosis of Eagle's syndrome is based on IHCD-3 [6] diagnostic criteria. Those criteria consist of any head, neck, pharyngeal and/or facial pain with at least two of the four following signs: Pain provoked or exacerbated by digital palpation of the stylohyoid ligament, pain provoked by head turning, pain improved by injection of local anaesthetic agent into the stylohyoid ligament, or by styloidectomy, or pain ipsilateral to the inflamed stylohyoid ligament. Also, there must be radiological evidence of a calcified or elongated stylohyoid ligament.

Eagle syndrome is diagnosed by radiography and physical examination. Pain during palpation of the tonsillar fossa could alert clinicians to this possible diagnosis Our case was a classic eagle syndrome associated with bilateral tonsil hypertrophy, treated several times previously as neuropathy pain by analgesic without significant result. There are many different etiologies that have been proposed to explain Eagle syndrome. three possible explanations was listed, which lead to abnormal stylohyoid complexes [7]. One of the theories relates to retained embryologic cartilage tissue from Reichert's cartilage. The second theory is calcification of the stylomandibular ligament. The third explanation is expansion of osseous tissue at the origin of the stylomandibular ligament.

In our case, Eagle syndrome was the main diagnostic hypothesis after physical and CT scan result. The symptomatic management of Eagle syndrome with conservative medical treatment, such as antiinflammatory medications, anticonvulsants, antipsychotics, or other analgesics is usually reserved for patients unable to undergo surgical procedure [8]. Surgical treatment presents remission of symptoms without the need for continuous drug use [9] and it is indicated for all patients due to it being the definitive treatment for this condition. The option for the surgical treatment in this case was taken, considering the age of patient, worsening of the symptoms reported by the patient and the definitive character of the intervention.

The surgical management of the Eagle syndrome consists in the shortening of the elongated styloid process, with the surgical access remaining a matter of dispute. Intraoral access consists of the first stage involving the resection of the palatine tonsil (if no tonsillectomy had been performed before) followed by the second stage involving the incision of the tonsillar bed mucosa and partial resection of the process. Benefits of this technique consist in the possibilities to avoid a skin scar. However, the technique is associated with a high risk of complications due to the poor visibility of the operating field resulting in a likelihood of important anatomical structures within the parapharyngeal space being damaged in the course of the procedure. Another complication may consist in the infection of the parapharyngeal space and the neck $[10,11]$. 
Eagle syndrome has a large variety of clinical presentations as evidenced by the multitude of nonspecific symptoms. As a result, it is important to understand the diagnostic workup, relevant imaging, and ultimate treatment options. Intraoral resection of styloid process remains the preferred surgical management.

\section{Acknowledgement}

None.

\section{Conflict of Interest}

No conflict of interest.

\section{References}

1. Balcioglu HA, Kilic C, Akyol M, Ozan H, Kokten G (2009) Length of the styloid process and anatomical implifications for Eagle's syndrome. Folia Morphol 68(4): 265-270

2. Fini G, Gasparini G, Filippini F, Becelli R, Marcotullio D (2000) The long styloid process syndrome or Eagle's Syndrome. Cranio-maxillofa Surg 28(2): 123-127.

3. Eagle W (1937) Elongated styloid process: report of two cases. Arch Otolaryngol 25: 584-586.
4. Sokler K, Sandev S (2001) New classification of styloid process lengthclinical application on the biological base. Coll Antropol 25(2): 627-632.

5. WW Eagle (1948) Elongated styloid process; further observations and a new syndrome. Arch Otolaryngol 47(5): 630-640.

6. (2018) Headache Classification Committee of the International Headache Society (IHS). The International Classification of Headache Disorders, ( $3^{\text {rd }}$ edn.), Cephalalgia 38: 1-211

7. RD Murtagh, JT Caracciolo, G Fernandez (2011) CT findings associated with eagle syndrome. AJNR Am J Neuroradiol 22(7): 1401-1402.

8. Fitzpatrick TH, Lovin BD, Magister MJ, Waltonen JD, Browne JD, et al. (2020) Surgical management of Eagle syndrome: A 17-year experience with open and transoral robotic styloidectomy. American Journal of Otolaryngology 41(2): 102324.

9. Ledesma Montes C, Hernández Guerrero JC, Jiménez Farfán MD (2018) Length of the ossified stylohyoid complex and Eagle syndrome. Eur Arch Otorhinolaryngol 275(8): 2095-2100.

10. Al Weteid AS, Miloro M (2015) Transoral endoscopic-assisted styloidectomy: How should Eagle syndrome be managed surgically? Int J Oral Maxillofac Surg 449: 1181-1187.

11. Beder E, Ozgursoy OB, Ozgurosy SK (2005) Current Diagnosis and Transoral Surgical Treatment of Eagle's Syndrome. J Oral Maxillofac Surg 63(12): 1742-1745. 